Instytut Archeologii UKSW

$w$ Warszawie

Michał Szubski

\title{
KRZEMIEŃ LOKALNY W OSADZIE UŻYTKOWNIKÓW? GOSPODARKA SUROWCOWA W KULTURZE CERAMIKI WSTĘGOWEJ RYTEJ NA STANOWISKU W BODZOWIE, WOJ. LUBUSKIE
}

Zarys treści. Materiał krzemienny związany z kulturą ceramiki wstęgowej rytej na stanowisku w Bodzowie (woj. lubuskie), przy małej liczbie wytworów z surowców importowanych, ma strukturę inwentarza charakterystyczną dla osad użytkowników.

Słowa kluczowe: kultura ceramiki wstęgowej rytej, gospodarka surowcowa, osada użytkowników, krzemień bałtycki.

Stanowisko $24 \mathrm{w}$ Bodzowie administracyjnie położone jest na granicy dzisiejszych województw lubuskiego i dolnośląskiego (ryc. 1); jest pierwszym w Polsce - odkrytym oraz badanym wykopaliskowo - neolitycznym obiektem typu rondel (Kobyliński, Nebelsick, Wach 2011; Kobyliński i in. 2012). Położone jest na lessowym cyplu wchodzącym w skład makroregionu Wału Trzebnickiego, na obszarze Wzgórz Dalkowskich (Kondracki 2013, s. 166-167). Dogodne osadniczo, lessowe wyniesienie, leżące w odległości $3 \mathrm{~km}$ od Odry, stanowiło w pradziejach miejsce rytualno-osadnicze. Badania wykopaliskowe na stanowisku były prowadzone w sezonach 2011-2012 przez Instytut Archeologii i Etnologii Polskiej Akademii Nauk przy współpracy z Instytutem Archeologii Uniwersytetu Kardynała Stefana Wyszyńskiego w Warszawie. W ich wyniku, oprócz rowów kulturowych, związanych prawdopodobnie z aktywnością społeczności kultury ceramiki kreskowo-kłutej, odkryto pozostałości osady kultury ceramiki wstęgowej rytej oraz kultury łużyckiej.

Szczególnie istotne okazały się materiały wczesnoneolityczne, stanowiące jeden z bogatszych zbiorów z dorzecza środkowej Odry. Na podstawie analizy materiałów ceramicznych z fazą klasyczną kultury ceramiki wstęgowej rytej powiązano 17 obiektów. Były to przede wszystkim jamy śmietniskowe 


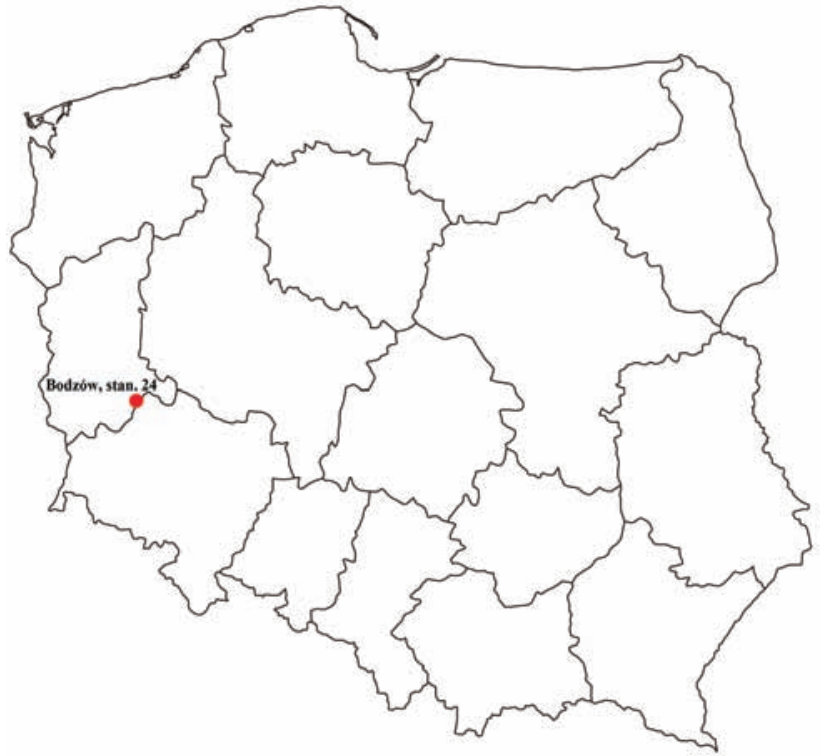

Ryc. 1. Bodzów, woj. lubuskie, stanowisko 24. Położenie administracyjne stanowiska (oprac. M. Szubski)

Fig. 1. Bodzów, Lubuskie voivodshp, site 24. Location of site (prepared by M. Szubski)

oraz rozległe glinianki charakterystyczne dla osad pierwszych rolników. Niestety, na stanowisku nie zachowały się pozostałości długich domów, co mogło być spowodowane niesprzyjającym, kwasowym charakterem gleby.

\section{METODYKA OPRACOWANIA ŹRÓDEL}

Zbiór materiałów krzemiennych liczył 90 wytworów pochodzących wyłącznie z jam kulturowych związanych z kulturą ceramiki wstęgowej rytej. $\mathrm{Z}$ uwagi na wielokulturowy charakter stanowiska nie można jednak wykluczyć domieszek materiałów młodszych, szczególnie związanych z kulturą ceramiki kreskowo-kłutej.

Przy opracowywaniu materiałów przyjęto standardowe metody stosowane w odniesieniu do inwentarzy krzemiennych, obejmujące makroskopową analizę surowcową i morfologiczną, uwzględniającą atrybuty technologiczne. Analiza surowcowa polegała na określeniu cech substancji krzemionkowej, stosowanym w polskiej archeologii od lat 20. XX wieku (Krukowski 1920; 1922). Uwzględnia ona cechy różnicujące skały krzemionkowe pochodzenia kopalnianego, co pozwoliło na wyodrębnienie materiałów importowanych w postaci krzemieni jurajskich, tzw. podkrakowskich (Kaczanowska, Ko- 
złowski 1976; Lech 1980a) oraz krzemieni czekoladowych (Schild 1971; Budziszewski 2008); odnotowano też materiały należące do grupy krzemieni narzutowych, tzw. bałtyckich (Dmochowski 2006). Surowce przegrzane oraz przepalone uznane zostały za grupę nieokreśloną surowcowo.

Analiza morfologiczno-typologiczna została oparta na klasycznym systemie klasyfikacji dynamicznej z podziałem na cztery grupy inwentarzowe (Dzieduszycka-Machnikowa, Lech 1976). Makroskopowa analiza technologiczna bazowała na pracach Wiliama Andrefsky'ego (2005) oraz - w przypadku wiórów - Marcina Wąsa (2011).

\section{STRUKTURA SUROWCOWA I MORFOLOGICZNA}

W literaturze przedmiotu istnieje teza o dominującej roli krzemieni jurajskich, podkrakowskich w wytwórczości krzemieniarskiej kultur wczesnoneolitycznych z terenu Dolnego Śląska (m.in. Balcer 1977, s. 8; 1983, s. 56-58; Lech 1979, s. 123, 131; 1981a, s. 224; 1997a, s. 237-239; Wojciechowski 1981, s. 92-98; 1988, s. 44-50). Na stanowisku w Bodzowie, znajdującym się na północnych peryferiach dolnośląskiego skupiska osadniczego, sytuacja ta przedstawia się inaczej. W opracowywanym inwentarzu zdecydowanie przeważa krzemień narzutowy, z którego wykonano 64\% wszystkich wytworów (ryc. 2). Podobnie surowiec ten dominuje też pod względem wagi - stanowi $79 \%$ zbioru.

Udział krzemieni importowanych $\mathrm{w}$ opisywanym inwentarzu wynosi $15 \%$, w tym surowca jurajskiego typu ,olszanickiego” $13 \%$ zbioru, natomiast czekoladowego jedynie 2\% (ryc. 2). Krzemienie przepalone/nieokreślone stanowią stosunkowo wysoki odsetek - $21 \%$ całego zbioru i $11 \%$ wagi wszystkich krzemieni. $Z$ uwagi na przekształcenie masy krzemionkowej w przypadku tych artefaktów nie można dokonać identyfikacji surowcowej. Znaczna przewaga krzemieni eratycznych może jednak sugerować, że materiał przepalony również należy do tej grupy surowcowej.

Struktura surowcowa materiałów krzemiennych kultury ceramiki wstęgowej rytej na stanowisku w Bodzowie przedstawia się odmiennie od tej, która cechuje inwentarze z podobnych chronologicznie stanowisk z dorzecza Odry. Należy jednak zaznaczyć, że na najbliższym, znanym z badań wykopaliskowych stanowisku w Głogowie, również dominuje krzemień narzutowy, przy około 30-procentowym udziale surowca jurajskiego, podkrakowskiego (Pogorzelski 1999). Struktura morfologiczna, w przeciwieństwie do struktury surowcowej, jest podobna jak w przypadku wspomnianego wyżej dolnośląskiego ośrodka osadniczego kultury ceramiki wstęgowej rytej. Największą 


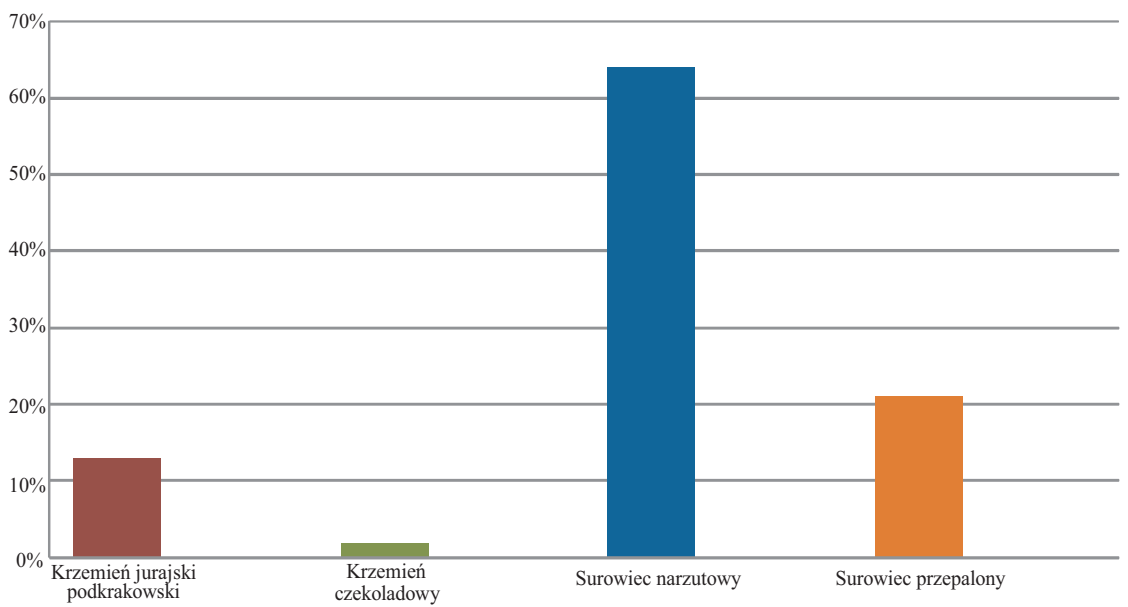

Ryc. 2. Bodzów, woj. lubuskie, stanowisko 24. Udział procentowy poszczególnych surowców krzemiennych w zbiorze kultury ceramiki wstęgowej rytej (oprac. M. Szubski)

Fig. 2. Bodzów, Lubuskie voivodshp, site 24. Percentage share of different raw materials in linearband pottery culture structure (prepared by M. Szubski)

grupę stanowią odłupki i odpadki (35\% zbioru), zbliżony odsetek narzędzia retuszowane (aż 31\% zbioru). Stosunkowo niski jest udział wiórów i ich fragmentów ( $27 \%$ zbioru), co może wynikać z odległej lokalizacji osady, do której półsurowiec docierał w gotowej postaci (Lech 1997a, s. 255). Tezę tę potwierdza również skromna liczba rdzeni - jedynie sześć okazów, stanowiących 7\% inwentarza (ryc. 3). Zbliżony ich udział odnotowano w inwentarzach z innych, podobnych chronologicznie stanowisk osadniczych z dorzecza górnej i środkowej Odry-rzadko przekracza on tam 10\% zbioru (Furmanek 2002, tab. III. 13).

\section{OSADY PRODUCENTÓW I OSADY UŻYTKOWNIKÓW}

Osady społeczności kultur wstęgowych w literaturze przedmiotu dzielone są na: osady producentów oraz użytkowników, które można rozróżnić na podstawie analiz inwentarzy krzemiennych (Lech 1983; 1991; 1997b; 2003). Osady producentów są zazwyczaj duże, z bardzo bogatym inwentarzem krzemiennym, składającym się przede wszystkim z pozostałości produkcji półsurowca. Prawdopodobnie były one ściśle związane ze znanymi stanowiskami pragórniczymi, łączonymi ze społecznościami wstęgowymi (Lech 1981b; Schild, Królik, Marczak 1985; Burnez-Lanotte, Allard 2003, s. 59-62). Pozostałości tego typu osad bez wątpienia pochodzą z podkrakowskiej Olszanicy (Milisauskas 1986) oraz Vedrovic-Zabrdovic na Morawach (Mateiciucová 


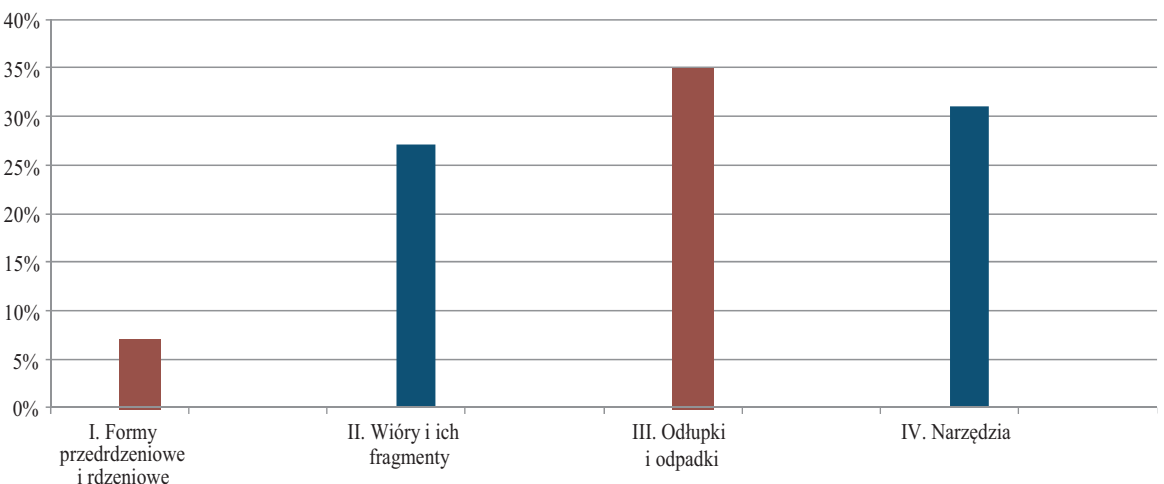

Ryc. 3. Bodzów, woj. lubuskie, stanowisko 24. Udział procentowy poszczególnych grup inwentarzowych w zbiorze kultury ceramiki wstęgowej rytej (oprac. M. Szubski)

Fig. 3. Bodzów, Lubuskie voivodshp, site 24. Percentage share of four morphological groups in linearband pottery culture structure (prepared by M. Szubski)

1995; 1997). Osady użytkowników to miejsca, gdzie krzemień docierał w postaci gotowego półsurowca wiórowego bądź narzędzi retuszowanych (Lech 2003, s. 22). W przypadku stanowisk w Samborcu (woj. świętokrzyskie), Strachowie, Niemczy i Skoroszowicach (woj. dolnośląskie) oraz Bylanach czy z Bravantic w Czechach (Lech 1981b; 1997a; 1989; 2008; Wojciechowski 1981; Pavlů 2000; Monik 2013) był to przede wszystkim kopalny krzemień jurajski, podkrakowski będący importem z miejsc położonych w pobliżu jego złóż.

Osady producentów i użytkowników można odróżnić na podstawie inwentarza krzemiennego - w tym drugim przypadku stosunek rdzeni i odłupków do wiórów i narzędzi retuszowanych wynosi od 45\% do 55\% (Lech 2003, s. 22). Oczywiście dominujący surowiec w inwentarzu stanowią krzemienie importowane. Osady takie są położone nieraz o kilkaset kilometrów od złóż krzemieni kopalnych. Surowce te, z uwagi na wysoką jakość oraz charakterystyczne cechy morfologiczne, związane były prawdopodobnie z rozbudowaną gospodarką wymienną. Istnieją przesłanki, że wśród społeczności kultur wstęgowych miały one szczególne znaczenie, związane z ich pozautylitarną rolą darów i odwzajemnienia (Lech 1990; Grooth de 1994; Małecka-Kukawka 1997; 2001, s. 173-177).

\section{OSADA UŻYTKOWNIKÓW Z BODZOWA}

Struktura surowcowa inwentarza kultury ceramiki wstęgowej rytej na stanowisku 24 w Bodzowie oparta jest na surowcu narzutowym bałtyckim. 
Sytuacja taka przemawiałaby raczej za lokalną obróbką krzemienia na własne potrzeby, uzupełnioną niewielką liczbą wytworów z surowców importowanych o wyraźnie lepszej jakości. Mimo to na podstawie struktury morfologicznej osadę należy zaliczyć do typu osad użytkowników.

W inwentarzu przeważają wióry oraz narzędzia retuszowane, które w stosunku do liczby rdzeni i odłupków stanowią 58\%:42\%. Do osady krzemień docierał prawdopodobnie $\mathrm{w}$ postaci półsurowca, mimo, że w zbiorze nie dominuje surowiec jurajski, podkrakowski, charakterystyczny dla osad użytkowników z południowo-zachodniej Polski. Niestety, słabo rozpoznany archeologicznie obszar województwa lubuskiego nie pozwala na dokładną lokalizację osady producentów, którą można by łączyć z osadą w Bodzowie. Trudne jest również jednoznaczne określenie źródła pochodzenia krzemieni eratycznych, z których wytwarzano półsurowiec docierający na teren stanowiska. Wątpliwe jest łączenie go z okręgiem głubczyckim (śląsko-morawskim) (Balcer 1980; 1983, s. 49; Lech 1980b). Mogły być to krzemienie pochodzące z obszarów położonych na północ od opisywanego stanowiska, czyli z rejonu Poznania-Starołęki bądź Międzychodu, gdzie wydobywano krzemień bałtycki (Kobusiewicz 1997; 1999). Najprawdopodobniej jednak źródłem surowców narzutowych były złoża położone w pobliżu stanowiska, eksploatowane przez nierozpoznane dotąd społeczności wstęgowe. Krzemień bałtycki, stosunkowo dobrej jakości, występuje obficie na terenie województwa dolnośląskiego (Bronowicki, Bobak 1999; Wiśniewski 2006) oraz lubuskiego.

Obecność krzemieni jurajskich, podkrakowskich może świadczyć o kontaktach z osadami wstęgowymi, prawdopodobnie z ośrodka dolnośląskiego (ryc. 4). Poświadczałoby to jego wyjątkową rolę, szczególnie, że na opisywanym stanowisku znaleziono przede wszystkim narzędzia i wióry z wymienionego surowca. Jan M. Burdukiewicz zwrócił jednak uwagę, że krzemienie wieku jurajskiego na terenie Dolnego Śląska występują w utworach wtórnych $^{2}$. Niewykluczone więc, że są one przypadkową domieszką surowców pochodzących z tych samych złóż co, reszta surowców narzutowych.

\footnotetext{
${ }^{1}$ Ustna informacja Janusza Budziszewskiego po badaniach powierzchniowych.

${ }^{2}$ Uwaga ta została zaprezentowana podczas dyskusji na konferencji pt. „Artefakt w przestrzeni: krzemienica, skupienie, stanowisko, region. 10. Warsztaty Krzemieniarskie SKAM (Stowarzyszenia Krzemieniarskiego)/Artefact in Spatial Arrangements: kshemienitsa, concentration, site, region. The $10^{\text {th }}$ SKAM Lithic Workshop" (23-25 października 2013 roku, Toruń).
} 


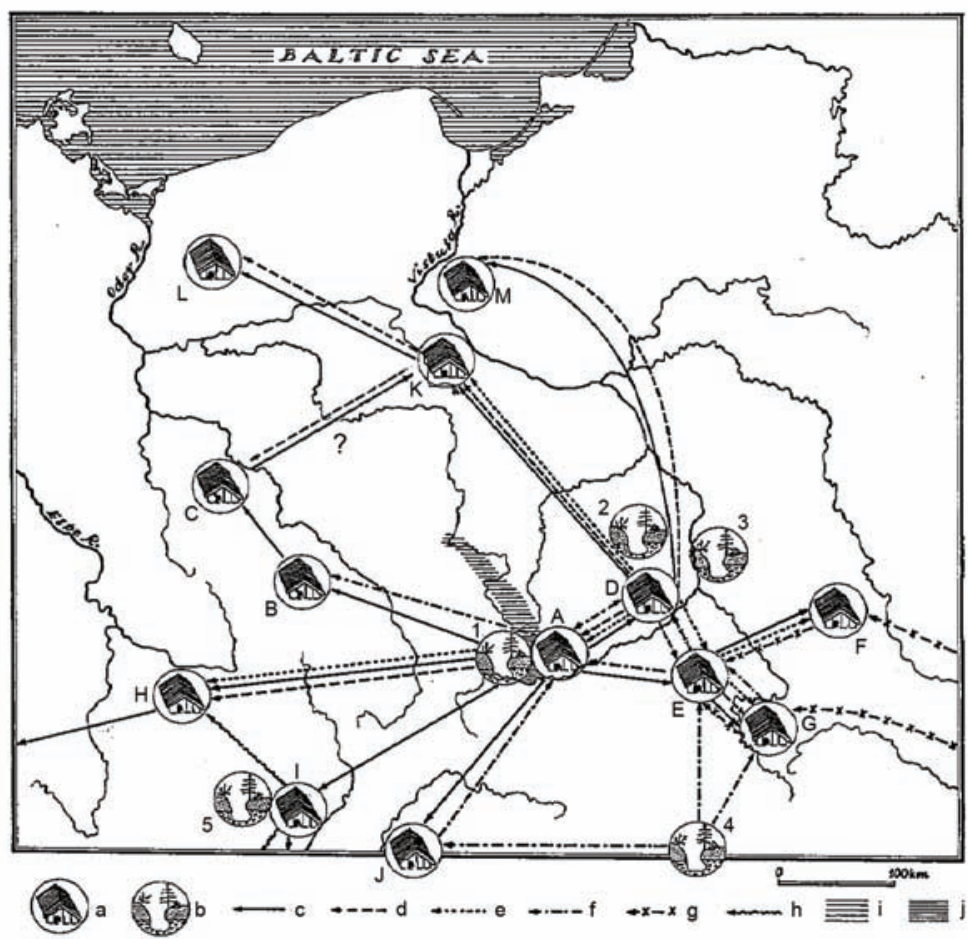

Ryc. 4. Mapa rozprzestrzeniania się surowców krzemiennych: a - osady; b - kopalnie; c - kierunek dystrybucji surowca jurajskiego, podkrakowskiego; d - kierunek dystrybucji surowca czekoladowego; e - kierunek dystrybucji surowca świeciechowskiego; f - kierunek dystrybucji obsydianu; g - kierunek dystrybucji krzemienia wołyńskiego; $\mathrm{h}$ - kierunek dystrybucji rogowców z obszaru Krumlovsky Les; i - Jura Polska; j - obszar występowania krzemienia jurajskiego, podkrakowskiego. A - Kraków-Olszanica, B - Strachów, C - Bodzów, D - Samborzec, E - Rzeszów, stanowisko 16, F - Tarnoszyn, G - Kormanice, H - Bylany, I - Vedrovice-Zabrodovice, J - Topolany-Jacovce, K - Brześć Kujawski, L - Żalęcino, M - Boguszewo, stanowisko 41. 1 - Sąspów, 2 - Tomaszów, 3 - Świeciechów, 4 - obsydian z południowo-wschodniej Słowacji, 5 - rogowiec z obszaru Krumlovsky Les (wg Lech 2003, z uzupełnieniami autora)

Fig. 4. Map of raw materials distribution among early farming communities: a - settlements; $b$ - mines; $c$ - direction of Jurassic-Cracow flint distribution; $d$ - direction of chocolate flint distribution; e - directions of grey white spotted flint (Świeciechów flint) distribution; $\mathrm{f}$ - directions of obsidian distribution; $\mathrm{g}$ - direction of Volhynian and Dnestr flint distribution; $\mathrm{h}$ - direction of hornstone from Krumlovsky Les area distribution; $\mathrm{i}$ - the Polish Jura; $\mathrm{j}$ - southern part of Polish Jura with deposits of Jurassic-Cracow flint. A - Cracow-Olszanica, B - Strachów, C - Bodzów, D - Samborzec, E - Rzeszów, site 16, F - Tarnoszyn, G - Kormanice, H - Bylany, I - Vedrovice-Zabrdovice, J - Topolany-Jacovce, K - Brześć Kujawski, L - Żalęcino, M - Boguszewo, site 41. 1 - Sąspów, 2 - Tomaszów, 3 - Świeciechów, 4 - exploitation of obsidian deposits in south-eastern Slovakia, 5 - exploitation of hornstone from the Krumlovsky Les area (after Lech 2003, with author's implement) 


\section{ZAKOŃCZENIE}

Stanowisko 24 w Bodzowie dostarczyło materiałów kultury ceramiki wstęgowej sugerujących istnienie regionu o gospodarce surowcowej odmiennej od znanych osad w południowo-zachodniej Polsce. Jednak brak dobrego rozpoznania tych terenów pod względem osadnictwa neolitycznego nie pozwala jednoznacznie odpowiedzieć na pytania dotyczące źródeł odkrytych surowców narzutowych.

\section{LITERATURA}

Andrefsky W. Jr.

2005 Lithics. Macroscopic approaches to analysis, second edition, Cambridge.

Balcer B.

1977 Z badań nad krzemieniarstwem neolitycznym w dorzeczu górnej Odry, Przegląd Archeologiczny, t. 25, s. 5-51.

1980 Materialy krzemienne ze stanowiska osadniczego w Pietrowicach Wielkich, [w:] Osady neolityczne w Pietrowicach Wielkich pod Raciborzem, red. J. Bukowska-Gedigowa, Wrocław, s. 159-193.

1983 Wytwórczość narzędzi krzemiennych w neolicie ziem polskich, Wrocław.

Bronowicki J., Bobak D.

1999 Schylkowopaleolityczna pracowania krzemieniarska z miejscowości Ślęża (stanowisko 12) pod Wrocławiem, Przegląd Archeologiczny, t. 47, s. $7-25$.

Budziszewski J.

2008 Stan badań nad występowaniem i pradziejowa eksploatacja krzemieni czekoladowych, [w:] Krzemień „czekoladowy” w pradziejach. Materialy z konferencji w Orońsku, 08-10.10.2003, red. W. Borkowski i in., Warszawa-Lublin, s. 33-106.

Burnez-Lanotte L., Allard P.

2003 Surplus production in the Belgian linearbandkeramik: Blade debitage at varlain „Petit Paradis” (Hesbaye, Belgium), [w:] Production and management of lithic materials in the European Linearbandkeramik, red. L. Burnez-Lanotte, Oxford, s. 59-65. 
Dmochowski P.

2006 A new classification of erratic flint from western Poland, [w:] The Stone: technique and technology, red. A. Wiśniewski, T. Płonka, J. M. Burdukiewicz, Wrocław, s. 217-229.

Dzieduszycka-Machnikowa A., Lech J.

1976 Neolityczne zespoły pracowniane z kopalni krzemienia w Saspowie, Polskie Badania Archeologiczne 19, Wrocław.

Furmanek M.

2002 Wczesny neolit na Śląsku, maszynopis w archiwum Instytutu Archeologii Uniwersytetu Wrocławskiego, Wrocław.

Grooth de M. E. Th.

1994 Studies on Neolithic flint exploitation. Socio-economic interpretation of the flint assemblages of Langweiler 8. Beek, Elsloo, Rijckholt, Hienheim and Meindling, Maastricht.

Kaczanowska M., Kozłowski J. K.

1976 Studia nad surowcami krzemiennymi poludniowo-wschodniej części Wyżyny Krakowsko-Częstochowskiej, Acta Archaeologica Carpathica, t. 26, s. 201-215.

Kobusiewicz M.

1997 Sources of Flint on the West Polish Plains, [w:] Man and flint. Proceedings of the VII-th International Flint-Symposium: Warszawa-Ostrowiec Świętokrzyski, September 1995, red. Z. Sulgostowska. Warszawa, s. $83-90$

1999 Ludy łowiecko-zbierackie północno-zachodniej Polski, Poznań.

Kobyliński Z., Nebelsick L. D., Wach D.

2011 Neolityczne obserwatorium astronomiczne (?) w Bodzowie na Ziemi Lubuskiej, Z otchłani wieków, R. 65, s. 27-32.

Kobyliński Z., Braasch O., Herbich T., Misiewicz K., Nebelsick L.D., Wach D.

2012 Confirmation of the first Neolithic rondel-type enclosure in Poland, Antiquity, t. 86, s. 1084-1096.

Kondracki J.

2013 Geografia regionalna Polski, Warszawa.

Krukowski S.

1920 Pierwociny krzemieniarskie górnictwa, transportu i handlu w holocenie Polski. Wnioski z własności surowców i wyrobów, Wiadomości Archeologiczne, t. 5, s. 185-206.

1922 Pierwociny krzemieniarskie górnictwa, transportu i handlu w holocenie Polski, cz. 2, Wiadomości Archeologiczne, t. 7, s. 34-57.

Lech J.

1979 Krzemieniarstwo w kulturze spoleczności ceramiki wstegowej rytej w Polsce. Próba zarysu, [w:] Początki neolityzacji w Polsce poludniowo-zachodniej, red. W. Wojciechowski, Wrocław, s. 121-136. 
1980a Geologia krzemienia jurajskiego-podkrakowskiego na tle innych skat krzemionkowych. Wprowadzenie do badań z perspektywy archeologa, Acta Archaeologica Carpathica, t. 20, s. 163-228.

1980b PL 13 Maków, gm. Pietrowice Wielkie, wojew. Katowice, [w:] 5000 Jahre Feuersteinbergbau. Die Suche nach dem Stahl der Steinzeit, red. G. Weisgerber, R. Slotta, J. Weiner, Bochum, s. 611.

1981a Górnictwo krzemienia społeczności wczesnorolniczych na Wyżynie Krakowskiej. Koniec VI tysiaclecia-1 połowa IV tysiąclecia p.n.e., Wrocław.

1981b Materiały krzemienne z osad społeczności wstęgowych w Niemczy, woj. Wałbrzych. Badania z lat 1971-1972, Silesia Antiqua, t. 23, s. 39-42.

1983 Flint mining among the early farming communities of Central Europe, Part II - The basis of research into flint workshops, Przegląd Archeologiczny, t. 30, s. 47-80.

1989 A Danubian raw material exchange network: a case study from Bylany, [w:] Bylany Seminar 1987. Collected Papers, red. J. Rulf, Praha, s. $111-120$.

1990 The organization of siliceous rock supplies to the early farming communities (LBK): Central European examples, [w:] Rubane et cardial. Actes du Colloque de Liège, novembre 1998, red. D. Cahen, M. Otte, Liège, s. 51-59.

1991 The Neolithic-Eneolithic transition in prehistoric mining and siliceous rock distribution, [w:] Die Kupferzeit als historische epoche. Symposium Saarbrucken and Otzenhausen 6-13.11.1998, red. J. Lichardus, Bonn, s. 557-574.

1997a Materiały krzemienne z osad społeczności wczesnorolniczych w Strachowie, woj. Wrocław, [w:] Strachów. Osiedla neolitycznych rolników na Ślasku, red. A. Kulczycka-Leciejewiczowa, Wrocław, s. 229-265.

1997b Remarks on prehistoric flint mining and flint supply in european archaeology, [w:] Silceous rocks and culture, red. A. Ramos-Millan, A. Bustillo, Grenada, s. 611-637.

2003 Mining and siliceous rock supply to the Danubian early farming communities (LBK) in eastern central Europe: A second approach, [w:] Production and management of lithic materials in the European Linearbandkeramik, red. L. Burnez-Lanotte, Oxford, s. 19-30.

2008 Materiały krzemienne społeczności kultury ceramiki wstęgowej rytej z Samborca, pow. Sandomierz, [w:] Samborzec. Studium przemian kultury ceramiki wstęgowej rytej, A. Kulczycka-Leciejewiczowa, Wrocław, s. 151-202.

Małecka-Kukawka J.

1997 Flint mining in south-eastern Poland and raw material „economy” of early farming communities in Chetmno Land. A social exchange theory 
perspective, [w:] Man and flint. Proceedings of the VII-th International Flint-Symposium: Warszawa-Ostrowiec Świętokrzyski, September 1995, red. Z. Sulgostowska, Warszawa, s. 243-247.

2001 Między forma a funkcją. Traseologia neolitycznych zabytków krzemiennych ziemi chetmińskiej, Toruń.

Mateiciucová I.

1995 CZ 4 Krumlovsky Les, Znojmo District, Archaeologia Polona, t. 33, s. 281-285.

1997 Local hornstiones among the first farmers (LBK) of the Krumlovsky Les Area, [w:] Man and flint. Proceedings of the VII-th International Flint-Symposium: Warszawa-Ostrowiec Świętokrzyski, September 1995, red. Z. Sulgostowska, Warszawa, s. 249-253.

Milisauskas S.

1986 Early Neolithic settlement and society at Olszanica, Michigan.

Monik M.

2013 Analysis of chipped and polished stone industries from the LBK settlement at Bravantice, [w:] Otázky neolitu a eneolitu našich krajín 2010, red. I. Cheben, M. Soják, Nitra, s. 197-214.

Pavlů I.

2000 Life on a Neolithic site Bylany: situational analysis of artefacts, Praha. Pogorzelski W.

1999 Wyniki ratowniczych badań wykopaliskowych na osadzie kultury ceramiki wstęgowej rytej, Głogów stan. nr 12, gm. Głogów, Dolnośląskie wiadomości prahistoryczne, t. 5, s. 7-16.

Schild R.

1971 Lokalizacja prahistorycznych punktów eksploatacji krzemienia czekoladowego na północno-wschodnim obrzeżeniu Gór Świętokrzyskich, Folia Quaternaria, t. 39, s. 1-61.

Schild R., Królik H., Marczak M.

1985 Kopalnia krzemienia czekoladowego w Tomaszowie, Wrocław.

Wąs M.

2011 „Janisławickie” i „wstegowe” koncepcje rdzeniowania wiórowego. Próba konfrontacji technologicznej, Acta Universitatis Lodziensis, Folia Archaeologica 28, s. 5-21.

Wiśniewski A.

2006 Środkowy paleolit w dolinie Odry, Wrocław.

Wojciechowski W.

1981 Wczesnoneolityczna osada w Skoroszowicach, Studia Archeologiczne 12, Wrocław.

1988 Kontakty Dolnego Śląska z Małopolską Zachodnią w neolicie i wczesnej epoce brąu w świetle tzw. importów, Silesia Antiqua, t. 30, s. 41-81. 


\section{ERRATIC FLINT IN USERS SETTLEMENT? SILICEOUS ROCK SUPPLY OF LINEARBAND POTTERY CULTURE IN BODZÓW, LUBUSKIE PROVINCE}

\section{Summary}

In linearband pottery culture (LBK) there were two main groups of settlement related to flint distribution. The first group were settlements of primary producers, which were located not far from raw materials sources (like Olszanica or Vedrovice). Second group were settlements of users which were located far from deposits of good quality raw materials and need to import prepared cores or even blades and tools. We can different them by comparing the raw material and morphological structure.

At site 24 in Bodzów, raw material structure based on erratic flint, which is unusual for users settlement. But morphological structure was very likely for users one with high amount of blades and tools, and very low amount of cores. Probably this raw materials were still imported to the site from, yet unknown, settlement of erratic flint producers in sites neighborhood.

Translated by Michat Szubski

Adres do korespondencji:

Michał Szubski

Instytut Archeologii

Uniwersytet Kardynała Stefana Wyszyńskiego w Warszawie

ul. Wóycickiego 1/3, bud. 23, 01-938 Warszawa

michal.szubski@gmail.com 